\title{
ABSENCE OF MESOTHELIAL CELLS FROM TUBERCULOUS PLEURAL EFFUSIONS
}

\author{
BY
}

\author{
A. I. SPRIGGS AND M. M. BODDINGTON \\ From the Churchill Hospital, Headington, Oxford
}

(RECEIVED FOR PUBLICATION NOVEMBER 26, 1959)

It is a commonplace of clinical teaching that tuberculous pleural effusions contain a high proportion of lymphocytes. This was one of two characteristics noticed by Widal (Widal and Ravaut, 1900), the other being an absence or scarcity of mesothelial ("endothelial") cells. This second feature is more constant than the first, but for some reason has escaped being generally known.

Looking back over stained films of pleural effusions from proved cases of tuberculosis, we found no case in which mesothelial cells were numerous enough to figure in an ordinary differential count. This feature is therefore much more constant than the lymphocytosis. We felt that it would be worth while to publish the data, since it appears that tuberculosis can be practically excluded as the cause of an effusion that contains numerous mesothelial cells.

\section{Material AND Methods}

We have re-examined the stained smears of deposits from all proved tuberculous pleural fluids observed in the past 10 years. We have only accepted those cases in which $M$. tuberculosis was found in the effusion, or in the sputum, or in gastric washings, and in which no other cause of the effusion, e.g., carcinoma, was known to be operating at the same time.

The series consists of 65 specimens from 59 patients. The pleural fluids were examined by the technique previously described (Spriggs, 1957); briefly, citrated fluid was centrifuged, air-dried films were made from the deposit (as concentrated as possible), and stained with May-Grünwald and Giemsa. Differential counts were made of 200 cells. The approximate frequency of mesothelial cells, if any, was estimated by counting all such cells in the film, and judging the total number of white cells in the film by its dimensions and by sample counts of whole microscopic fields.

\section{identification of Mesothelial Cells}

The cytological features of effusions have been described by Spriggs (1957), and only a brief remark will be made here.

The term "mesothelial cells" is used to include all the cells with entire round or oval nuclei, and excludes the cells of mesothelial origin with nuclei that are folded or compressed by cytoplasmic vacuoles. The latter are classified as "macrophages." In inflammatory effusions, mesothelial cells usually have strongly basophilic cytoplasm. Mesothelial cells are shown in Fig. 1 in an effusion with a high percentage of lymphocytes due to carcinoma of the lung. A macrophage from a tuberculous effusion containing only $74.5 \%$ of lymphocytes is shown in Fig. 2. Fig. 3 shows the typical appearance of a tuberculous effusion, with a very high proportion of lymphoid cells and no mesothelial cells.

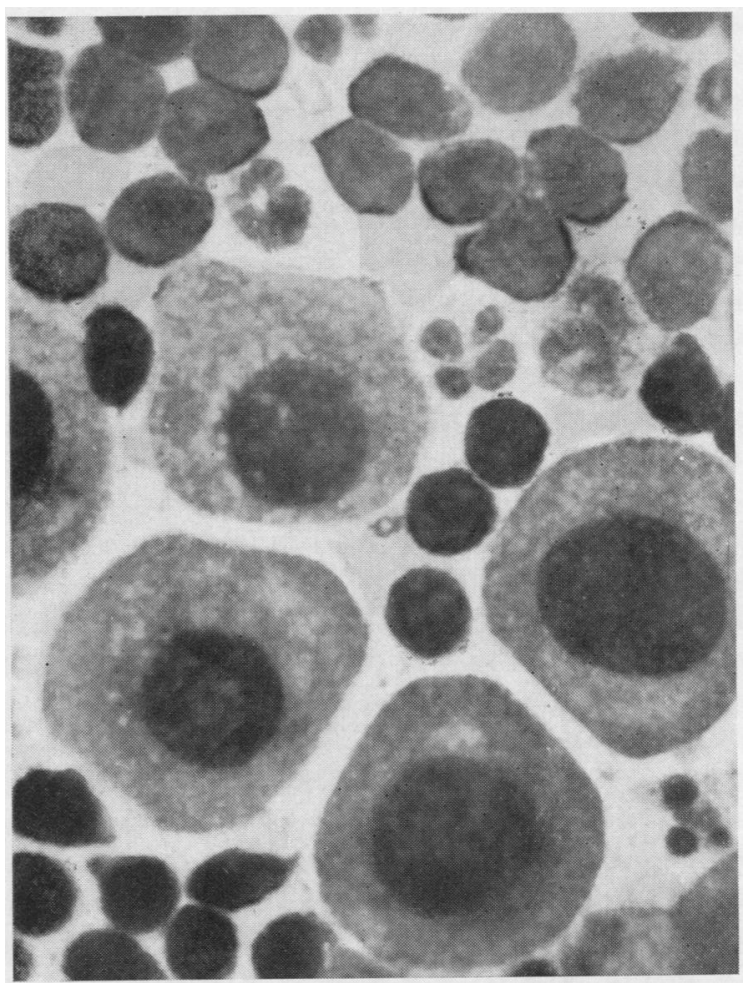

FIG. 1.-Mesothelial cells, lymphocytes, and a few neutrophils in a pleural effusion due to carcinoma of the lung. The presence of the mesothelial cells with basophilic cytoplasm practically excludes a diagnosis of tuberculous effusion. $(\times 1,200$. 
There is often a considerable variety of lymphoid cells, sometimes including cells of the plasmacyte series. These may show mitoses, and immature forms (plasmablasts) may be confused with mesothelial cells unless the smears are of good quality.

\section{RESULTS}

Fig. 4 is a scatter diagram which includes all the specimens examined, except for six with deposits consisting only of blood, pus, or cholesterol crystals. It illustrates the lymphocyte percentage, and the proportion of mesothelial cells per 10,000 white cells. The lymphocyte percentage is usually high, but this is not invariable. The mesothelial cells, on the other hand, are always very scarce. There is only one point near the top, representing 25 mesothelial cells per 10,000 . In this case the pleura was tapped within a few days of the onset of the effusion. It should be noted that even this shows a proportion of mesothelial cells far below that found in most types of pleural effusion.

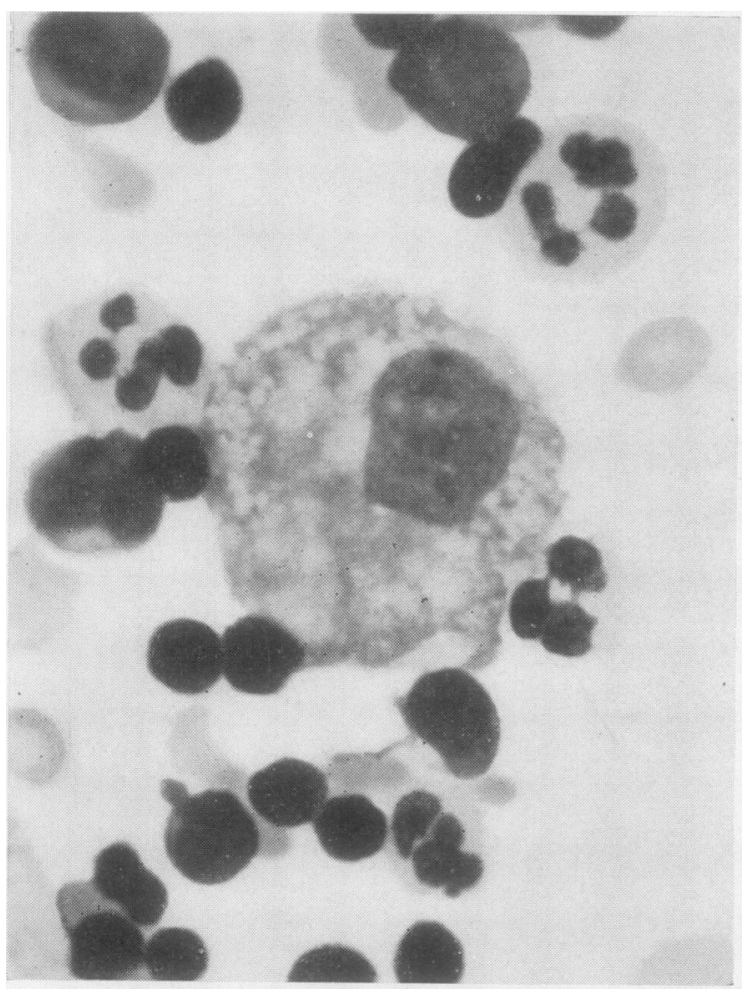

FIG. 2.-Pleural effusion complicating pulmonary tuberculosis. In this fluid there were numerous neutrophils as well as lymphocytes, and a large macrophage is also shown. The last has a foamy cytoplasm and an irregular nuclear outline. Such cells may occasionally be found in numbers in tuberculous effusions. $(\times 1,200$. $)$

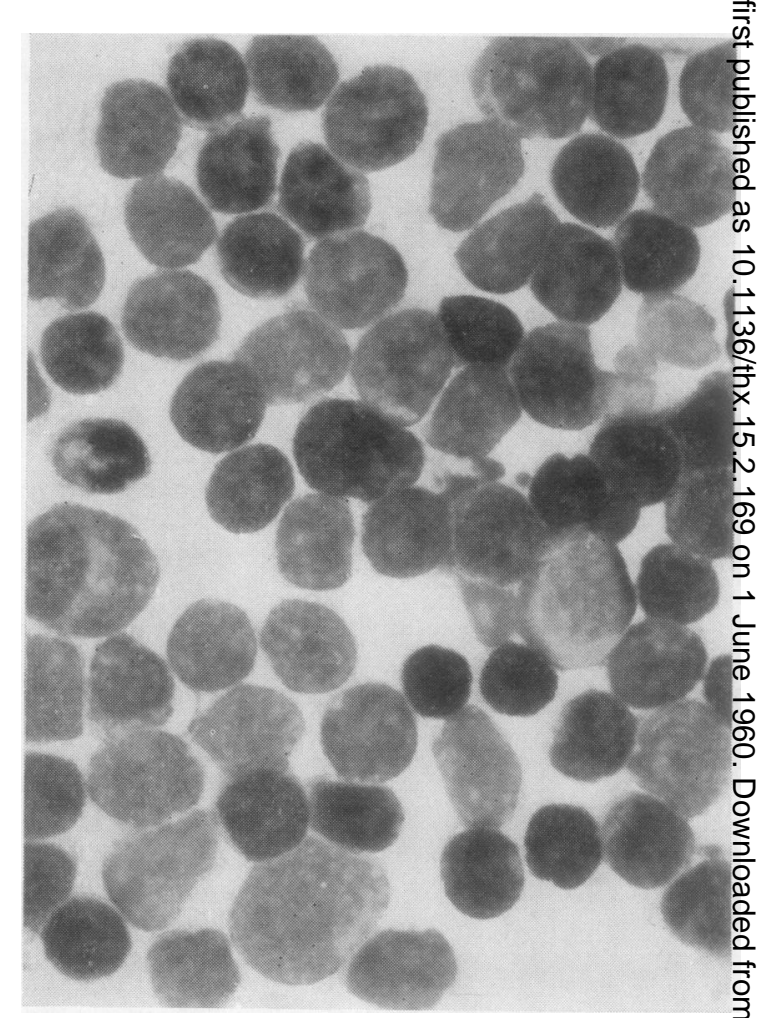

FIG. 3.-Typical tuberculous pleural effusion. Nearly all the cells are lymphocytes. A plasma cell is shown on the left. $(\times 1,200$.

\section{Discussion}

The scarcity of mesothelial cells in tuberculous pleural effusions has been previously stressed by a $\dot{\sigma}$ number of authors (Widal, Ravaut, and Dopter, $\underline{3}$. 1902 ; Dieulafoy, 1901 ; Königer, 1908 ; Zadek, ô 1933). They have also pointed out that when such 3 cells are found in the first days of the effusion 을 they very soon disappear. In our series there were 10 specimens containing more than one mesothelial cell per 10,000 white cells. Of these, the duration of symptoms was less than one week (two or cases), one week (three cases), two weeks (two N cases), three weeks (one case), four weeks (one $\mathcal{W}^{-}$ case), and in one case the time of onset could not be estimated. In two of the above-mentioned cases a second specimen a few days after the first showed the disappearance of the mesothelial cells. In one of these the symptoms were already said to be of three weeks duration, but it is of course impossible to be sure that an effusion had been present for that length of time.

The explanation for the disappearance of mesothelial cells from tuberculous pleural effusions is probably that the serous membrane 8 


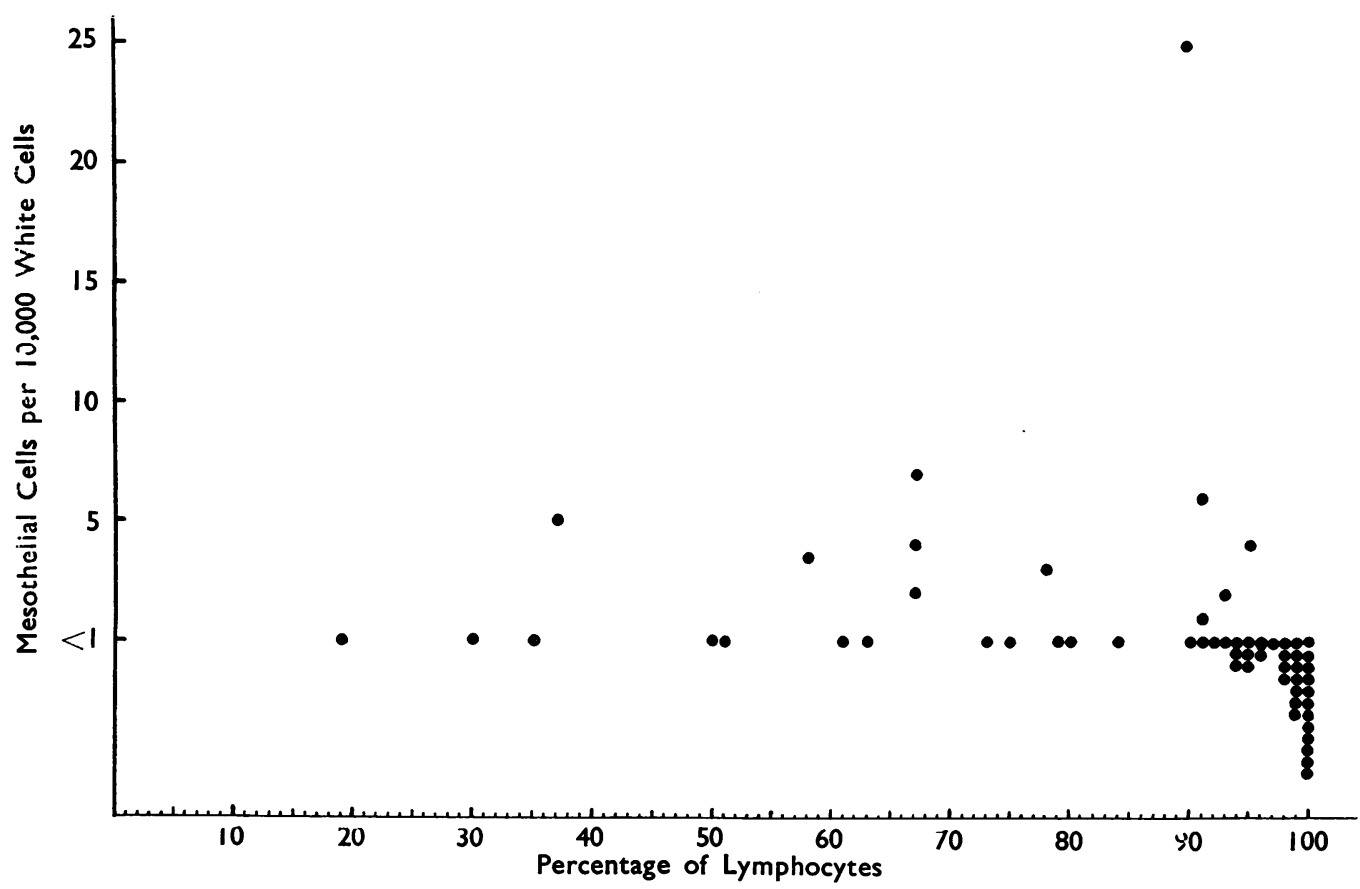

FIg. 4.-Each dot represents a specimen of pleural fluid. Vertical scale, mesothelial cells per 10,000 white cells. Horizontal scale, percentage of lymphocytes.

becomes covered by a fibrinous layer and subsequently is destroyed by the growth of tuberculous granulation tissue. Saltykow (1901) found in some cases an intact mesothelial layer beneath the fibrin or tuberculous tissue, but this has not been found by Mestitz, Purves, and Pollard (1958) in pleural biopsy material. The latter authors demonstrate in their photographs the distinction between a tuberculous pleura apparently lacking mesothelium and a pleura showing mesothelial proliferation, which histologically is not seen in tuberculosis. Most probably the tuberculous process involves the whole pleural surface area. Pollard (personal communication) has never found a normal mesothelial lining in pleural biopsy material from cases of tuberculosis, although admittedly the samples only come from a limited area.

In practice, the diagnostic usefulness of a cytological report on a possibly tuberculous effusion is greatly increased if an opinion is also given about the frequency of the mesothelial cells. If they are scarce or absent, tuberculosis is a possibility even when lymphocytes do not predominate. If mesothelial cells are numerous enough to figure in a percentage differential count, tuberculosis is highly unlikely, and some other explanation should be sought for the effusion.

\section{SUMMARY}

A cytological examination has been made of 65 specimens of pleural fluid from 59 cases of tuberculosis proved bacteriologically.

In no instance were mesothelial cells found in a proportion greater than 2.5 per 1,000 white cells.

The absence or scarcity of mesothelial cells is a more constant character than the lymphocytosis.

A pleural effusion which contains frequent mesothelial cells can be assumed to be due to some cause other than tuberculosis.

We are grateful to Dr. A. H. T. Robb-Smith and to Dr. E. A. Spriggs for their criticism of the manuscript. Both the authors receive grants from the British Empire Cancer Campaign.

\section{REFERENCES}

Dieulafoy, G. (1901). Sem. méd. (Paris), 21, 377.

Königer, H. (1908). Die zytologische Untersuchungsmethode. Fischer, Jena.

Mestitz, P., Purves, M. J., and Pollard, A. C. (1958). Lancet, $2,1349$. Salt ykow, S. (1901). Beitr. path. Anat., $29,233$.

Spriggs, A. I. (1957). The Cytology of Effusions. Heinemann, London.

Widal and Ravaut (1900). C.R. Soc. biol. (Paris), 52, 648, 651, and 653.

Zadek, I (1933) "Die (1902). Ibid., 54, 1005. . Transsudate", in Handbuch der allgemeinen Hämatologie, ed. Hirschfeld, $H$. and Hittmair, A. Vol. 1, p. 1373. Urban and Schwarzenberg, Berlin. 